\title{
Venous popliteal entrapment syndrome
}

\author{
Christine K. Chen, Marcin Kolber \\ Department of Radiology, University of Texas Southwestern Medical Center, Dallas, TX, USA \\ Contributions: (I) Conception and design: Both authors; (II) Administrative support: None; (III) Provision of study materials or patients: None; (IV) \\ Collection and assembly of data: None; (V) Data analysis and interpretation: None; (VI) Manuscript writing: Both authors; (VII) Final approval of \\ manuscript: Both authors. \\ Correspondence to: Christine K. Chen, MD. Department of Radiology, University of Texas Southwestern Medical Center, 5323 Harry Hines Blvd., \\ Dallas, TX 75390-8834, USA. Email: Christine.Chen@utsouthwestern.edu.
}

\begin{abstract}
Popliteal entrapment syndrome (PES) describes a set of symptoms related to compression of the neurovascular bundle in the popliteal fossa, with popliteal artery involvement the most widely recognized variation. Popliteal vein entrapment is a rare variation which can easily go undiagnosed. This is most commonly due to an anomaly of the medial head of the gastrocnemius muscle, but other etiologies include excess adipose tissue or cysts within the popliteal fossa, popliteal artery aneurysm, fibrous bands, thickened perivenous fascia, compression by the popliteus muscle or muscular hypertrophy independent of anomalous anatomy, or variant origin of the short saphenous vein. However, with improving awareness, it is a condition which should be increasingly considered in patients presenting with unexplained lower extremity swelling or other symptoms of lower extremity thrombosis. The initial test of choice is typically ultrasound with flexion and extension maneuvers. Venography is the gold standard for diagnosis, but MRI offers a noninvasive option for both diagnosis and evaluation of etiology and should be considered in the work-up of popliteal venous entrapment. Management is based on severity and type of symptoms, ranging from conservative management with compression stockings to surgical management if there is popliteal artery involvement or more severe symptoms. Endovascular therapy such as angioplasty or stenting has also been reported with good results.
\end{abstract}

Keywords: Popliteal vein entrapment; popliteal vein compression; venous compression

Submitted Feb 25, 2020. Accepted for publication Jun 29, 2020.

doi: $10.21037 / \mathrm{cdt}-20-292$

View this article at: http://dx.doi.org/10.21037/cdt-20-292

Popliteal entrapment syndrome (PES) describes a set of symptoms related to compression of the popliteal artery, vein, tibial nerve, or any combination of the above in the popliteal fossa sufficient to cause neurovascular symptoms.

\section{Pathophysiology}

The popliteal neurovascular bundle normally courses between the medial and lateral heads of the gastrocnemius muscle. When the knee is fully extended and locked, the medial and lateral heads of the gastrocnemius muscle relax, increasing their bulk. This increased bulk can result in popliteal vein compression, a normal variant, seen in $27 \%$ of healthy adults assessed with ultrasound (1) and observed as an incidental finding in $42 \%$ of limbs undergoing ascending venography (2). When pathologic, this entity is referred to as popliteal vein entrapment. The most common cause of popliteal vein entrapment is an anomaly of the medial head of the gastrocnemius muscle (2), such as lateral extension of the origin of the medial head of the muscle or an anomalous third head of the gastrocnemius muscle $(3,4)$. Popliteal vein entrapment can be seen in combination with popliteal artery entrapment, with $10-15 \%$ of patients with popliteal arterial entrapment also demonstrating venous involvement (5), but less commonly can also occur in isolation. Other causes include excess adipose tissue in the popliteal compartment, popliteal fossa cyst, popliteal artery aneurysm, fibrous band, thickened perivenous fascia, popliteus muscle, muscular 
hypertrophy without anomalous anatomy, and anomalous origin of the short saphenous vein (5-9).

\section{Historical context}

The anatomic basis for entrapment was first described in 1879 by medical student T. P. Anderson Stuart, describing the popliteal artery as "pass[ing] almost vertically downwards internally to the inner head of the gastrocnemius. It reaches the bottom of the space by turning round the inner border of that head, and then passes downwards and outwards beneath it...” (10). In 1959, a similar anomaly was described by Hamming, who also described successfully surgical exploration and treatment for the first time with thrombectomy and repositioning of the head of the gastrocnemius muscle (11). The phrase "popliteal artery entrapment syndrome" was first used by Love and Whelan in 1965 (12) and became widely accepted to describe the anomaly. A 1967 case report by Rich and Hughes (13) in 1967 reported for the first time involvement of the popliteal vein. Unlike prior reports, they did not observe medial looping of the popliteal artery, but rather lateral attachment of the medial head of the gastrocnemius muscle to the mid-femur with resultant vascular compression. In 1978 Connell reported the first case of isolated popliteal vein entrapment (3).

As recognition of PES has increased, so have attempts to categorize causative anomalies. An early classification system proposed by Rich et al. (14) described five types: Type 1 was abnormal course of the popliteal artery around a normally placed medial head of the gastrocnemius muscle; Type 2 was abnormal lateral attachment of the gastrocnemius muscle covering the popliteal artery; Type 3 was due to accessory slips or heads of the medial head of the gastrocnemius muscle attached more laterally than normal; Type 4 was due to fibrous bands or the popliteus muscle causing compression of the popliteal artery; and Type 5 included Types 1-4 but with popliteal vein involvement.

\section{Clinical presentation}

The most common presenting symptom is limb swelling (15), which may be in combination with other symptoms of chronic venous insufficiency such as below the knee edema, leg heaviness, varicosities, pain with ambulation in the absence of arterial pathology, dermal hyperpigmentation or venous ulceration. Despite these findings of chronic venous insufficiency, no superficial venous insufficiency is identified on venous duplex examination, or the patient may undergo endovenous therapy for superficial venous reflux with return of presenting symptoms shortly after the procedure, as described by Dijkstra (6). Patients can also present initially with venous thrombosis and require treatment before the diagnosis can be confirmed (16).

\section{Imaging and diagnosis}

The initial test of choice is typically ultrasound. The popliteal vein should be evaluated with the knee flexed, and then with the knee extended with plantar flexion of the foot to evaluate for significant compression, indicated by decreased diameter of the vessel and/or decreased phasicity (17). However, as noted previously, changes in vessel caliber may be physiologic. CT venogram can be used to evaluate for compression and surrounding anatomy which may cause compression, but is limited by ionizing radiation exposure and more difficult timing for bright venous opacification (18). More recently, MRI with MRV has become an important modality for evaluation of venous compression. Like CT, MRI can characterize anomalous anatomy which may cause venous compression. Additionally, flow-sensitive sequences allow for assessment of venous flow direction, which can suggest hemodynamic significance of compression. Additionally, the availability of blood-pool contrast agents such as gadofosveset trisodium (Vasovist; Bayer Schering, Berlin, Germany) extends the window in which vascular images can be acquired up to 1 hour (19). When evaluating suspected venous disease, steady state imaging with this contrast agent has the advantage of increased vessel enhancement and potential to perform imaging in both the neutral position and with provocative maneuvers. The gold standard confirmatory test is ascending venography with provocative maneuvers, on which compression should be demonstrated with the knee fully extended and the foot plantar flexed $(16,20)$. Popliteal compartment pressures or popliteal vein pressures can also be measured $(2,6)$.

\section{Treatment and outcomes}

Management is based on severity and type of symptoms. Patients presenting with thrombosis should be treated with anticoagulation, and possible catheter-directed thrombolysis as indicated. Mild symptoms can be managed with compression stockings. In those with concomitant popliteal arterial entrapment or more severe symptoms, surgical decompression with or without popliteal vein 
reconstruction can be considered. Endovascular treatment such as angioplasty or stenting is also reported (21).

Raju and Neglen (2) analyzed 30 patients undergoing surgical popliteal vein decompression with severance of the medial head of the gastrocnemius and release of any muscular and fibrous compression bands. After surgery, pain improved in $76 \%$ of patients and was completely resolved in $48 \%$. Swelling improved in $63 \%$ and was completely resolved in $41 \%$. Clinical outcome was considered excellent in $41 \%$ of patients and improved in $38 \%$ of patients. Hirokawa et al. (22) reviewed 11 patients who underwent partial or total resection of the medial or third head of the gastrocnemius muscle under venographic and venous pressure measurement guidance for symptomatic popliteal vein entrapment and found $57 \%$ had symptom resolution and $21 \%$ had symptom improvement. Milleret (23) also reviewed a series of 11 cases of popliteal vein entrapment treated with surgical muscle/band section and aponeurectomy and demonstrated symptom improvement in $9 / 11$ patients $(82 \%)$.

Garrie et al. described endovascular treatment of 14 patients (21), with 5 patients undergoing angioplasty alone, 4 treated with angioplasty and stenting in the same initial procedure, and 5 undergoing angioplasty only initially but requiring subsequent re-intervention. In total, $50 \%$ of patients underwent stenting. All patients demonstrated immediate improvement of symptoms in the first 1-2 weeks. Nine out of 14 (64\%) remained asymptomatic throughout the follow-up period, which averaged 5 months. The other 5 patients reported recurrence of symptoms and underwent secondary intervention, 2 with repeat angioplasty alone and 3 with stenting. All reported resolution of symptoms after secondary intervention. No patient in this study underwent open surgical decompression within the follow-up period.

\section{Conclusions}

Popliteal vein entrapment is a rare entity which can easily go undiagnosed. However, with improving awareness, it is a condition which should be increasingly considered in patients presenting with unexplained lower extremity swelling or other symptoms of thrombosis. Venography is the gold standard for diagnosis, but MRI offers a noninvasive option for both diagnosis and evaluation of etiology and should be considered in the work-up of popliteal venous entrapment.

\section{Acknowledgments}

Funding: None.

\section{Footnote}

Provenance and Peer Review: This article was commissioned by the editorial office, Cardiovascular Diagnosis and Therapy for the series "Compressive Vascular Syndromes". The article has undergone external peer review.

Conflicts of Interest: Both authors have completed the ICMJE uniform disclosure form (available at http:// dx.doi.org/10.21037/cdt-20-292). The series "Compressive Vascular Syndromes" was commissioned by the editorial office without any funding or sponsorship. MK served as the unpaid Guest Editor of the series. The authors have no other conflicts of interest to declare.

Ethical Statement: The authors are accountable for all aspects of the work in ensuring that questions related to the accuracy or integrity of any part of the work are appropriately investigated and resolved.

Open Access Statement: This is an Open Access article distributed in accordance with the Creative Commons Attribution-NonCommercial-NoDerivs 4.0 International License (CC BY-NC-ND 4.0), which permits the noncommercial replication and distribution of the article with the strict proviso that no changes or edits are made and the original work is properly cited (including links to both the formal publication through the relevant DOI and the license). See: https://creativecommons.org/licenses/by-nc-nd/4.0/.

\section{References}

1. Leon M, Volteas N, Labropoulos N, et al. Popliteal vein entrapment in the normal population. Eur J Vasc Surg 1992;6:623-7.

2. Raju S, Neglen P. Popliteal vein entrapment: A benign venographic feature or a pathologic entity? J Vasc Surg 2000;31:631-41.

3. Connell J. Popliteal vein entrapment. Br J Surg 1978;65:351.

4. Iwai T, Sato $S$, Yamada T, et al. Popliteal vein entrapment caused by the third head of the gastrocnemius muscle. $\mathrm{Br} \mathrm{J}$ 
Surg 1987;74:1006-8.

5. Gerkin TM, Beebe HG, Williams DM, et al. Popliteal vein entrapment presenting as deep venous thrombosis and chronic venous insufficiency. J Vasc Surg 1993;18:760-6.

6. Dijkstra ML, Khin NY, Thomas SD, et al. Popliteal vein compression syndrome pathophysiology and correlation with popliteal compartment pressures. J Vasc Surg Venous Lymphat Disord 2013;1:181-6.

7. Nottingham JM, Haynes JL. Isolated Popliteal Vein Entrapment by a Fibrous Band: A Case Report. Vasc Surg 2001;35:487-90.

8. Misselbeck T, Dangleben D, Celani V. Isolated popliteal vein entrapment by the popliteus muscle: a case report. Vasc Med 2008;13:37-9.

9. Banjo AO. Aberrant popliteus muscle: anatomy and clinical consideration. Afr J Med Med Sci 1996;25:69-73.

10. Stuart TP. Note on a Variation in the Course of the Popliteal Artery. J Anat Physiol 1879;13:162.

11. Hamming JJ. Intermittent claudication at an early age, due to an anomalous course of the popliteal artery. Angiology 1959;10:369-71.

12. Love JW, Whelan TJ. Popliteal artery entrapment syndrome. Am J Surg 1965;109:620-4.

13. Rich NM, Hughes CW. Popliteal artery and vein entrapment. Am J Surg 1967;113:696-8.

14. Rich NM, Collins GJ, Mcdonald PT, et al. Popliteal Vascular Entrapment: Its Increasing Interest. Arch Surg 1979;114:1377-84.

Cite this article as: Chen CK, Kolber M. Venous popliteal entrapment syndrome. Cardiovasc Diagn Ther 2021;11(5):1168-1171. doi: 10.21037/cdt-20-292
15. Sinha S, Houghton J, Holt PJ, et al. Popliteal entrapment syndrome. J Vasc Surg 2012;55:252-262.e30.

16. White JM, Comerota AJ. Venous Compression Syndromes. Vasc Endovascular Surg 2017;51:155-68.

17. Iyer S, Angle JF, Uflacker A, et al. Venous Compression Syndromes: a Review. Curr Treat Options Cardiovasc Med 2017;19:45.

18. Zucker EJ, Ganguli S, Ghoshhajra BB, et al. Imaging of venous compression syndromes. Cardiovasc Diagn Ther 2016;6:519-32.

19. Beitzke D, Wolf F, Juelg G, et al. Diagnosis of popliteal venous entrapment syndrome by magnetic resonance imaging using blood-pool contrast agents. Cardiovasc Intervent Radiol 2011;34 Suppl 2:S12-S16.

20. Butros SR, Liu R, Oliveira GR, et al. Venous compression syndromes: clinical features, imaging findings and management. Br J Radiol 2013;86:20130284.

21. Garrie A, Jones LE, Chen JF, et al. New Vein Compression Entities in Patients with Unexplained Leg Swelling. Ann Vasc Surg 2017;45:173-8.

22. Hirokawa M, Iwai T, Inoue $Y$, et al. Surgical Treatment of Popliteal Vein Entrapment Causing Symptoms. Phlebol J Venous Dis 2002;17:103-7.

23. Milleret R. Popliteal vein entrapment: an unrecognized cause of failure in surgery for superficial venous insufficiency. Phlebolymphology 2007;14:31-6. 